\title{
Nearly Total Obstruction of Ascending Aorta by Intimal Flap in Tip 1 Aortic Dissection
}

\author{
Okay Güven Karaca*, Ayse Gül Kunt, Mehmet Kalender, \\ Mehmet Taşar, Ata Niyazi Ecevit, Osman Tansel Darçın \\ Cardiovascular Clinics, Konya Education and Research Hospital, Konya, Turkey \\ Email: ${ }^{*}$ drguven@gmail.com
}

Received November 27, 2012; revised December 29, 2012; accepted January 6, 2013

\begin{abstract}
Acute Type I aortic dissections are fast progressing highly mortal vascular emergencies if management delays. In this particular paper we report a case with a Type I aortic dissection mistreated for first 2 hours as thrombotic AMI, and aortic dissection diagnosis confirmed and treated surgically immediately. 59 years old male patient admitted to emergency room with sudden onset chest pain. Patient was seen by cardiologist and with NSTMI diagnosis admitted to Coronary ICU. With the suspicion of aortic dissection patient was scanned with contrasted thoraco-abdominal CT. Exam revealed subtotal occlusion of ascending aorta by flap of De Bakey Type I aortic dissection. In conclusion aortic dissection should be considered in differential diagnosis of chest pain. Clinical suspicion aortic dissection is key point of diagnosis and immediate confirmation may be life saving.
\end{abstract}

Keywords: Acute; Aortic Dissection

\section{Introduction}

Acute Type I aortic dissections are fast progressing highly mortal vascular emergencies if management delays. Autopsy studies showed $50 \%$ of patients die in first 48 hours, of remaining $84 \%$ die in first month and of survivals $90 \%$ will be death at the end of 3 months [1]. Medial degenerasyon (cystic medial necrosis), marfan, turner, noonan and ehlers-danlos syndrome, bicuspid aortic valve, dilated ascending aorta (greater than 5.0 to $5.5 \mathrm{~cm}$ ), atherosclerosis, aortic coarctation, systemic arterial hypertension, closed chest trauma, pregnancy, aortic cannulation, and intramural hematoma are associated with aortic dissection [2,3]. Aortic dissection may cause to AMI (Acute myocardial Infarction) in 1\% - 3\% frequency [4]. But management of AMI subsequent to dissection differs from thrombotic AMI. In this particular paper we report a case with a Type I aortic dissection mistreated for first 2 hours as thrombotic AMI, and aortic dissection diagnosis confirmed and treated surgically immediately.

\section{Case Report}

59 years old male patient admitted to emergency room with sudden onset chest pain and accompanying back pain on 2nd hours of symptoms. Patient was seen by car-

\footnotetext{
"Corresponding author.
}

diologist and with NSTMI diagnosis admitted to Coronary ICU, antiplatelet and anticoagulant therapy was started (Figure 1). Patologic Q wave was seen at inferior EKG derivations. On admittance lab results were as following; wbc: $11.2 \mathrm{~K} / \mu \mathrm{L}, \mathrm{hb}: 12.4 \mathrm{gr} / \mathrm{dL}$, htc: $38 \%$, urea: $39 \mathrm{mg} / \mathrm{dL}$, creatinin: $1.05 \mathrm{mg} / \mathrm{dL}, \mathrm{Na}: 141 \mathrm{mEg} / \mathrm{L}, \mathrm{K}: 4.4$ $\mathrm{mEg} / \mathrm{L}, \mathrm{Ca}: 9.3 \mathrm{mEg} / \mathrm{L}$, troponin I: $0.65 \mathrm{ng} / \mathrm{mL}$. While patient was in ICU, chest X-ray revealed widened mediastinum (Figure 2). With the suspicion of aortic dissection patient was scanned with contrasted thoraco-abdominal CT. Exam revealed subtotal occlusion of ascending aorta by flap of De Bakey Type I aortic dissection (Figure 3). Patient underwent urgent surgery. After median sternotomy, right femoral and right axillary arterial canulations and right atrial two-stage venous cannulations completed. Venting cannula inserted to right superior pulmonary vein and retrograt cardioplegia cannula introduced in coronary sinus. CPB started and cross clamping was achived. Retrograde cardioplegia started and ascending aorta opened. There was no tear in ascending aorta. On totally circulatuar arrest arcus aorta evaluated. There was a tear on small curvature. Ascending aorta and hemiarcus replaced by using $28 \mathrm{~mm}$ Dacron graft. Right coronary artery bypassed by saphenous vein graft. CPB terminated without any problem. Drains and pacing wire were placed and patient went to the cardiovascular intensive care unit. 


\section{Discussion}

Acute type I aortic dissection is a vascular emergencybecause needs rapid diagnosis and management that should be focused by cardiologists, thoracic and vascular surgeons. Patients generally present with chest pain and mostly described as sharp, tearing or as ripping [5]. But $15 \%-20 \%$ of patients may not experience chest pain [6]. Additional to chest and back pain any focal neurological deficit, hypotension, tamponade, hypertension, any pulse deficit, aortic regurgitation and abdominal pain may be the main complain of patients with aortic dissection [7]. Because of arch vessel occlusion, stroke occurs in 5\% to $10 \%$ of patients with type I dissection [8]. Type I dissection also causes paraplegia, oliguria and anuria. Suspicion of aortic dissection plays a key point in clinical diagnosis because symptoms, signs, ECG and chest radiograph changes are not sensitive nor specific [9]. But after clinical suspicious, diagnosis is confirmed with some form of imaging studies (computerized tomography, tran-

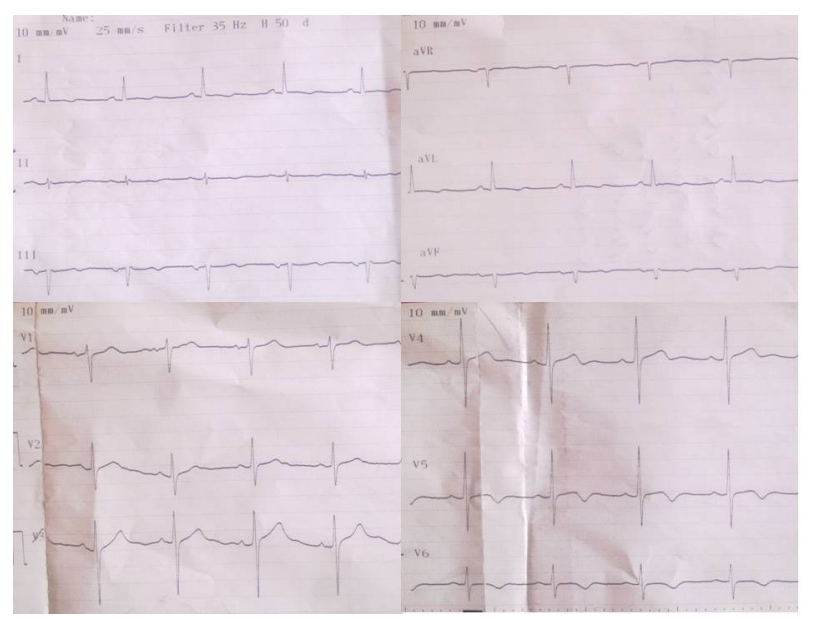

Figure 1. No acute change in ECG.

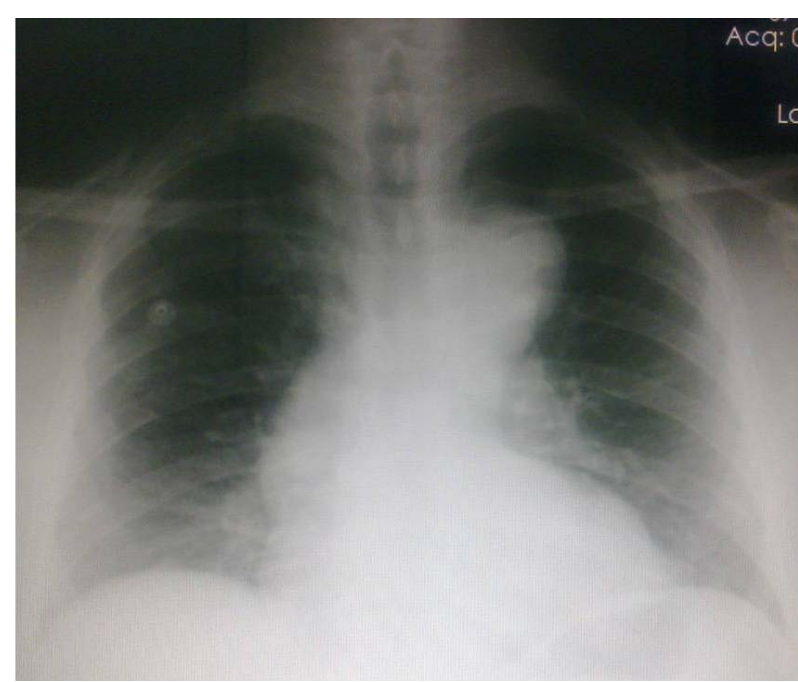

Figure 2. Widened mediastinum revealed by chest X-ray.

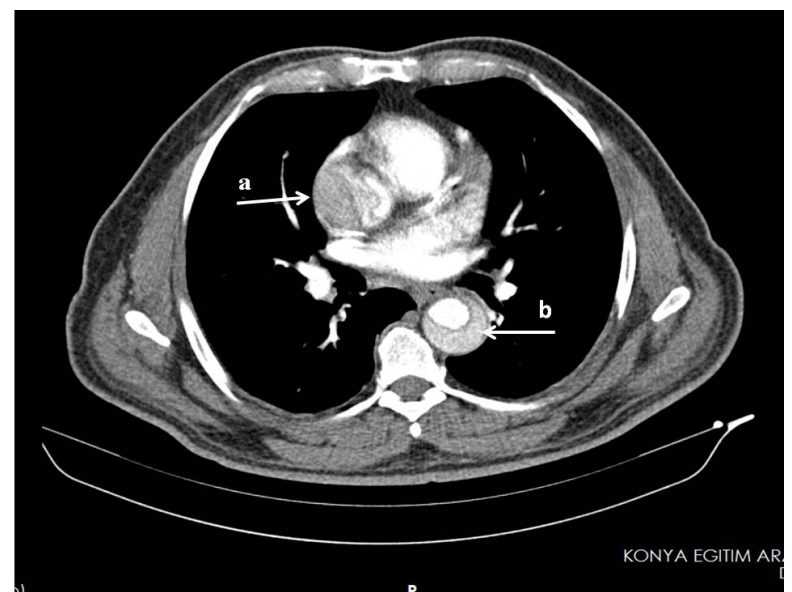

Figure 3. (a) Subtotal occlusion of ascending aorta; (b) Flap in desending aorta.

sesophageal echocardiography, magnetic resonance imaging, or aortography). Aortic dissection is rarely diagnosed immediately, but mostly diagnosis delays may also infrequently be misdiagnosed $[10,11]$. In the case of aortic dissection suspicion management algorithm may be beneficial [12,13], (Table 1). The ECG and Cardiac troponin estimations are primarily used to facilitate acute coronary syndromes and do not discriminate between acute coronary syndrome and dissection [14].

Malperfusion phenomenon after dissection can be in several ways; it might occur due to fixed or dynamic flap occlusion of the aorta or branch artery or secondary to compromised flow in the supplying false lumen or true lumen due to thrombosis of the former and compression of the latter [15]. $10 \%-15 \%$ of cases are due to coronary malperfusion [16]. In literature it is reported that RCA is more vulnerable to be effected from aortic dissection comparing to left coronary arterial system [10]. Half of the patients with coronary malperfusion first diagnosed as acute coronary syndrome and treated with antiplatelet and thrombolytic therapy.

Coronary artery disease rate in patients with type I aortic dissection is believed to be low. In emergency cases it is not an obligation to have a coronary angiography to these patients [17]. Because catheterization may cause aortic rupture or aortic malperfusion and also catheterization may delay operation [13]. But in stable patients, coronary angiography may be applied.

Surgical resection of ascending aorta in patients with type I aortic dissection is standard treatment [18]. Aim of surgery is resection and replacement with prosthetic graft of ascending and/or arch of aorta segment effected with intimal tear [18]. Operative technique is decided due to condition of aortic valve, coronary ostiums and experience of surgeon. Right hemiarch replacement $(27 \%)$, aortic-valve replacement (24\%), and coronary artery bypass (15\%) might be needed [7]. Endovascular stent graft 
Table 1. Initial management pathways in suspected acute aortic dissection (BP: blood pressure, ECG: electrocardiogram).

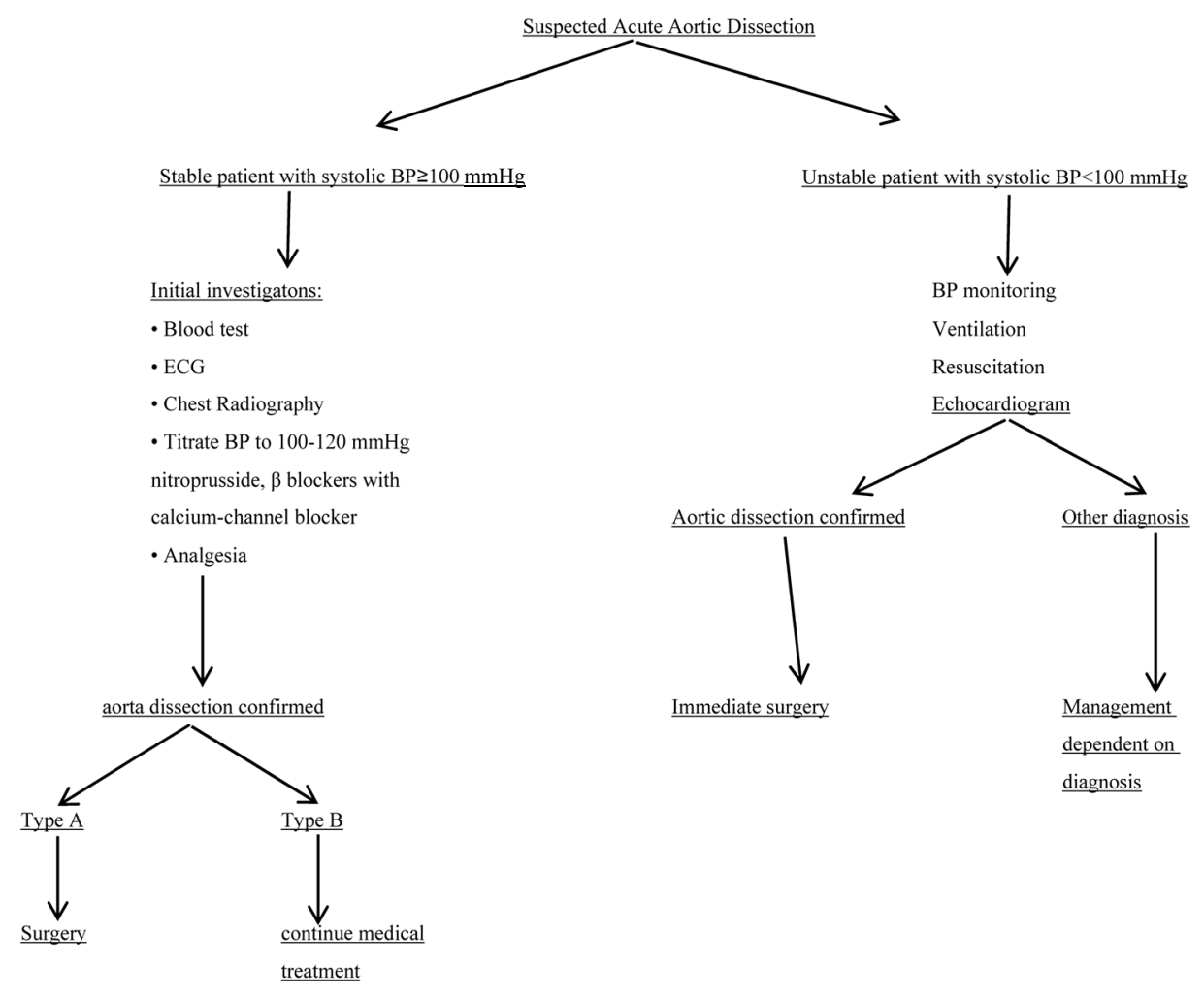

placement may be combined to these procedures but management are unclear [19] IRAD study reported mortality of type I aortic dissection after surgical treatment as $24 \%$ [7].

In our case, due to patient's symptom was typical angina and cardiac troponin levels were elevated without ECG change NSTMI was first diagnosis. And treatment started with antiplatelet and thrombolytic regimens. After chest X-ray, dissection was suspected and thoracic CT scan was applied and diagnosis of type I aortic dissection was confirmed.

In conclusion aortic dissection should be considered in differential diagnosis of chest pain. Clinical suspicion aortic dissection is key point of diagnosis and immediate confirmation may be life saving.

\section{REFERENCES}

[1] C. E. Anognostopoulos, M. J. Prabhakar and C. F. Kittle, "Aortic Dissections and Dissecting Aneurysms," American Journal of Cardiology, Vol. 30, No. 3, 1971, pp. 263273. doi:10.1016/0002-9149(72)90070-7

[2] E. W. Larson and W. D. Edwards, "Risc Factors for Aortic Dissection: A Necropsy Study of 161 Cases," American Journal of Cardiology, Vol. 53, No. 6, 1984, pp. 849855. doi:10.1016/0002-9149(84)90418-1

[3] S. K. Wilson and G. M. Hutchins, "Aortic Dissecting Aneurysms: Causative Factors in 240 Subjects," Archives of Pathology \& Laboratory Medicine, Vol. 106, No. 4,

1982, pp. 175-180.

[4] E. Neri, T. Toscano, U. Papalia, G. Frati, M. Massetti, G. Capannini, E. Tucci, D. Buklas, L. Muzzi, L. Oricchio and C. Sassi, "Proximal Aortic Dissection with Coronary Malperfusion: Presentation, Management, and Outcome," Journal of Thoracic and Cardiovascular Surgery, Vol. 121, No. 3, 2001, pp. 552-560. doi:10.1067/mtc.2001.112534

[5] J. S. Collins, A. Evangelista, C. A. Nienaber, et al., "International Registry of Acute Aortic Dissection (IRAD). Differences in Clinical Presentation, Management, and Outcomes of Acute Type a Aortic Dissection in Patient with and without Previous Cardiac Surgery," Circulation, Vol. 110, Suppl. 1, 2004, pp. 237-242. doi:10.1161/01.CIR.0000138219.67028.2a

[6] H. Eggebrecht, C. K. Naber, C. Bruch, et al., "Value of Plasma Fibrin D-Dimers for Detection of Acute Aortic Dissection," Journal of the American College of Cardiology, Vol. 44, No. 4, 2004, pp. 804-809. doi:10.1016/j.jacc.2004.04.053

[7] V. Rampoldi, S. Trimarchi, K. A. Eagle, et al., "International Registry of Acute Aortic Dissection (IRAD) Inverstigators. Simple Risk Models to Predict Surgical Mortality in Acute Type A Aortic Dissection: The International Registry of Acute Aortic Dissection Score," Annals of Thoracic Surgery, Vol. 83, No. 1, 2007, pp. 5561. doi:10.1016/j.athoracsur.2006.08.007

[8] J. I. Fann, J. A. Smith, D. C. Miller, R. S. Mitchell, K. A. Moore, G. Grunkemeier, et al., "Surgical Management of Aortic Dissection during a 30-Year Period," Circulation, 
Vol. 92, 1995, pp. 113-121. doi:10.1161/01.CIR.92.9.113

[9] R. Erbel, F. Alfonso, C. Boileau, et al., "Diagnosis and Management of Aortic Dissection: Task Force on Aortic Dissection," European Heart Journal, Vol. 22, 2001, pp. 1642-1681. doi:10.1053/euhj.2001.2782

[10] J. W. Olin and V. Fuster, "Acute Aortic Dissection: The need for Rapid, Accurate, and Readily Available Diagnostic Strategies," Arteriosclerosis, Thrombosis, and Vascular Biology, Vol. 23, 2003, pp. 1721-1723. doi:10.1161/01.ATV.0000093222.33222.D2

[11] P. C. Spittell, J. A. Spittell, J. W. Joyce, et al., "Clinical Features and Differential Diagnosis of Aortic Dissection: Experience with 236 Cases (1980 through 1990)," Mayo Clinic Proceedings, Vol. 68, No. 7, 1993, pp. 642-651. doi:10.1016/S0025-6196(12)60599-0

[12] R. Erbel, F. Alfonso, C. Boileau, et al., "Task Force on Aortic Dissection," European Heart Journal, Vol. 22, 2001, pp. 1642-1681. doi:10.1053/euhj.2001.2782

[13] J. Golledge and K. A. Eagle, "Acute Aortic Dissection," Lancet, Vol. 372, No. 9632, 2008, pp. 55-66. doi:10.1016/S0140-6736(08)60994-0

[14] R. S. Bonser, A. M. Ranasinghe, M. Loubani, et al., "Evidence, Lack of Evidence, Controversy, and Debate in the Provision and Performance of the Surgery of Acute Type A Aortic Dissection," Journal of the American College of Cardiology, Vol. 58, No. 24, 2011, pp. 24552474.
[15] M. K. Heinemann, B. Buehner, H. J. Schaefers, M. J. Jurmann, J. Lass and H. G. Borst, "Malperfusion of the Thoracoabdominal Vasculature in Aortic Dissection," Journal of Cardiac Surgery, Vol. 9, No. 6, 1994, pp. 748-755. doi:10.1111/j.1540-8191.1994.tb00910.x

[16] E. Neri, T. Toscano, U. Papalia, et al., "Proximal Aortic Dissection with Coronary Malperfusion: Presentation, Management, and Outcome," Journal of Thoracic and Cardiovascular Surgery, Vol. 121, No. 3, 2001, pp. 552560. doi:10.1067/mtc.2001.112534

[17] J. S. Miller, S. A. LeMaire and J. S. Coselli, "Evaluating Aortic Dissection: When Is Coronary Angiography Indicated?" Heart, Vol. 83, No. 6, 2000, pp. 615-616. doi:10.1136/heart.83.6.615

[18] R. Erbel, F. Alfonso, C. Boileau, et al., "Task Force on Aortic Dissection, European Society of Cardiology. Diagnosis and Management of Aortic Dissection," European Heart Journal, Vol. 22, 2001, pp. 1642-1681. doi:10.1053/euhj.2001.2782

[19] C. A. Mestres, C. Fernandez, M. Josa and J. Mulet, "Hybrid Antegrade Repair of the Arch and Descending Thoracic Aorta with a New Integrated Stent-Dacron Graft in Acute Type A Aortic Dissection: A Look into the Future with New Devices," Interactive CardioVasc Thoracic Surgery, Vol. 6, No. 2, 2007, pp. 257-259. doi:10.1510/icvts.2006.141010 